\title{
Green Synthesis of Clean Edge Graphene Nanosheets Using Natural Precursor
}

\author{
BALAKRISHNAN SOMASEKARAN ${ }^{1 *}$, ALWARSAMY THIRUNARAYANASWAMY1, \\ ILAMATHI PALANIVEL ${ }^{2}$ \\ ${ }^{1}$ Department of Mechanical Engineering, Government College of Technology, Coimbatore, 641013, India \\ ${ }^{2}$ Department of Production Engineering, Government College of Technology, Coimbatore, 641013, India
}

\begin{abstract}
Graphene, a two-dimensional crystalline allotrope of carbon, has received greater attention from numerous researchers due to its excellent properties. Graphene could be produced by various techniques, each method has its advantages and disadvantages. In this research article, a novel method using agricultural waste rice husk as a precursor and chemical activation to produce few-layer graphene nanosheets was developed. Traditional approaches' significant shortcomings and the environmental concern of agricultural waste have been eliminated. The synthesized material was characterized using FESEM, Raman Spectroscopy, X-Ray diffractometer, UV-Vis absorbance and FTIR analysis. FESEM analysis of the surface morphology revealed smooth edge few-layer graphene. The formation of $s p^{2}$ hybridized atoms can be seen in XRD spectra at 26.3 degrees. The $C=C$ stretching bonds detected at $1612 \mathrm{~cm}^{-1}$ wavelength are responsible for the graphitic structure.
\end{abstract}

Keywords: graphene, green synthesis, natural precursor, characterization

\section{Introduction}

Nanomaterials created a revolutionary impact on new generation materials in food packaging, pharmaceuticals, energy storage, electronics, wastewater treatment because of the excellent thermal and electrical conductivity, high surface area to volume ratio, exceptional strength and resilience. The effect of the implication of nanocarbons in electrochemistry, tribology, drug delivery, optics, biomedical imaging, hydrogen storage has provided a unique outlook to the nano dimensional materials. Due to their peculiar properties, nano carbons such as graphene, fullerenes and carbon nanotubes have intrigued the interest of many researchers such as mechanical stability, light scattering and adsorption, electrochemical flexibility, high conductivity and good corrosion resistance [1,2].

Since its discovery in 2004, graphene has paved a novel outlook for multiples of new generation materials. Graphene is a single-layered atom thickness $2 \mathrm{D}$ crystalline material in which $\mathrm{sp}^{2}$ hybridized carbon atoms are stacked and tightly bound together by Vanderwall force in the shape of a regular hexagonal lattice pattern having an atomic distance of $0.142 \mathrm{~nm}[3,4]$. All graphitic products could be derived from graphene since being the fundamental component. Fullerene can be made from a single graphene layer (OD), graphene can be rolled to form a carbon nanotube (1D), multiples of graphene sheets are stacked together to form a graphite (3D) structure [5]. The unique characteristics of graphene have gained massive attention among researchers. Graphene being the stiffer and thinnest material has an inherent strength of $13 \mathrm{GPa}$ and the Young's modulus of monolayer graphene is approximately 1.0 TPa. [6,7]. It has a high intrinsic electron mobility of $200,000 \mathrm{~cm}^{2} \mathrm{v}^{-1} \mathrm{~s}^{-1}$ and its low resistivity $(1 \mu \Omega . \mathrm{cm})$, ability to resist the current density of $108 \mathrm{~A} / \mathrm{cm}^{2}$ finds application in supercapacitors, sensors, highperformance transistors, high-conductivity composites, and high-strength composites [8-10]. The thermal conductivity of graphene is around $5000 \mathrm{Wm}^{-1} \mathrm{k}^{-1}$, which is exceptional [11].

In mechanical exfoliation, the graphite is peeled off to produce graphene employing scotch tape [12].

It is the simplest method to produce a few layers of graphene, but the yield obtained is less.

*email:sbalkrishs@gmail.com 
The liquid phase exfoliation technique uses a solution in which graphite is dispersed in organic solvent and then further sonicated to separate the graphene layers. The sonicated solution is then centrifuged at different frequencies to produce pristine graphene [13]. It is a time-consuming process and the synthesized graphene is not of uniform thickness [14].

Chemical exfoliation is also known as the hummers process in which graphene oxide is produced by oxidizing using chemical substances $\mathrm{NaNO}_{3}$ and $\mathrm{KMnO}_{4}$. Further, the graphene oxide is reduced to derive graphene. Even though the yield is high, the defects on graphene sheets are inevitable. The complexity of the process is the usage of toxic reducing agents and the liberation of hazardous gases [15]. Carbon atoms are made to deposit on a substrate to produce graphene using chemical vapor deposition. The process molecules were maintained at a particular pressure and temperature for the reaction to occur and the gaseous reactants are generally deposited on nickel or copper substrate $[16,17]$. High quality and high purity graphene could be achieved. However, it has its disadvantage like difficulty in achieving uniform deposition of carbon, operating at high temperature, the complication in thickness control [18]. Thermally heating the single crystalline silicon carbide leads to epitaxial growth of graphene sheets on SiC. The layers can be controlled and ordered graphene can be produced. The high operating temperature is the principal disadvantage of this process [19].

Graphene synthesis by conventional methods has its advantages and disadvantages. These led researchers to focus on a green cost-effective method for synthesis, which includes using natural precursors and reducing the usage of toxic chemicals. In this research work, agricultural waste was used to synthesize graphene and characterized by various techniques.

\section{Materials and methods}

The dismissal and environmental issue of agricultural waste rice husk ash (RHA) has implied its usage as reinforcement in many applications. The researchers have focused on it because of its significant elements $\mathrm{SiO}_{2}(91 \%)$, carbon (4\%), $\mathrm{Al}_{2} \mathrm{O}_{3}(3 \%)$ and minor traces of $\mathrm{CaO}, \mathrm{MgO}, \mathrm{Fe}_{2} \mathrm{O}_{3}$ and $\mathrm{K}_{2} \mathrm{O}$. These elements have created a significant impact on the fields of production of high purity silicon nanoparticles, silicon carbide, amorphous silica, porous carbon, silicon nitride, binder and insulating material in construction and refractory industries; activated carbons from RHA acts as anti-cleansing agents and also a suitable material for water purification. The amorphous silica derived from RHA is used in applications of waterproofing chemicals, solar panels, bio-fertilizers, cosmetics, anti-caking agents for the food packaging industry, flame retardants [20-22].

Rice husk $(\mathrm{RH})$ was retrieved from the agricultural fields and rinsed thoroughly with distilled water to eliminate impurities and other contaminants, further dried for $24 \mathrm{~h}$. The brown RH was converted to black RHA through the charring process of heating at $200^{\circ} \mathrm{C}$ for $1 \mathrm{~h}$ in the air. Three grams of carbon-rich RHA were mixed with $15 \mathrm{~g}$ of chemically activating agent potassium hydroxide $(\mathrm{KOH})$ and ground using a mortar for $15 \mathrm{~min}$. The mixture was compacted and covered with ceramic wool and sacrificial RHA in a porcelain crucible to resist oxidation at high temperatures. A large ceramic crucible was used to accommodate the crucible. RHA was annealed in the furnace for $2 \mathrm{~h}$ at $800^{\circ} \mathrm{C}$ to activate it. To eradicate the entrapped $\mathrm{k}$ elements, the sample was stirred for 6-7 $\mathrm{h}$ in deionized water after the chemical activation treatment. After that, the solution was filtered and treated with deionized water several times. The resulting sample was dried at $100^{\circ} \mathrm{C}$ for $24 \mathrm{~h}$. Figure 1 depicts the process of green synthesis of graphene from $\mathrm{RH}$.

The synthesized material was further characterized by various characterization techniques. The microstructure of graphene nanosheets was studied using a field emission scanning electron microscope (FESEM). X-ray diffraction (XRD) running at a constant scan speed of 10 degrees per minute with a $\mathrm{Cu}-\mathrm{K} \alpha$ radiation source $\left(\lambda=1.54 \mathrm{~A}^{\mathrm{o}}\right)$ and scan range from 5 to 80 degrees at a constant voltage of $40 \mathrm{kV}$ and $30 \mathrm{~mA}$ was used to investigate the crystal structure. After dissipating the obtained graphene powder in distilled water and evaluating the spectra against distilled water as a reference, the absorbance of graphene was investigated using a UV-Vis double beam spectrometer [23]. The sample's size distribution was determined using a zetasizer nano ZS 90 (Malvern instruments) by dispersing the 


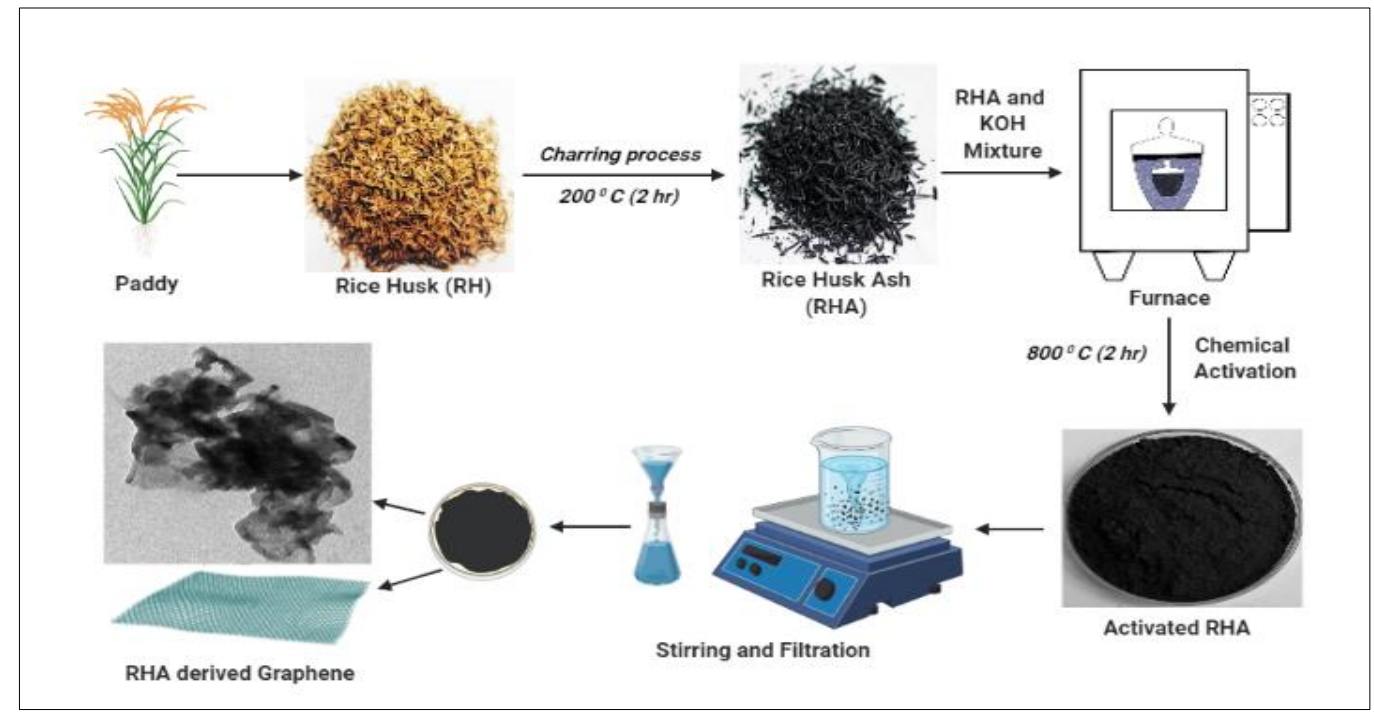

Figure 1. Schematic process flow chart for green synthesis of graphene using agricultural waste

sample in distilled water. Fourier transform infrared (FTIR) spectra in the range of $4000-400 \mathrm{~cm}^{-1}$ were recorded on a Perkin Elmer spectrometer. Raman spectroscopy (LabRAM HR800) at $532 \mathrm{~nm}$ excitation wavelength at room temperature is used to determine the vibrational modes of molecules in the sample.

\section{Results and discussions}

The surface morphology examined in FESEM is shown in Figure 2. It is clear that thin layered structures of graphene flakes were formed with sharp edges employing the insinuation of potassium atoms into the rice husk ash, causing the elimination of amorphous carbon.

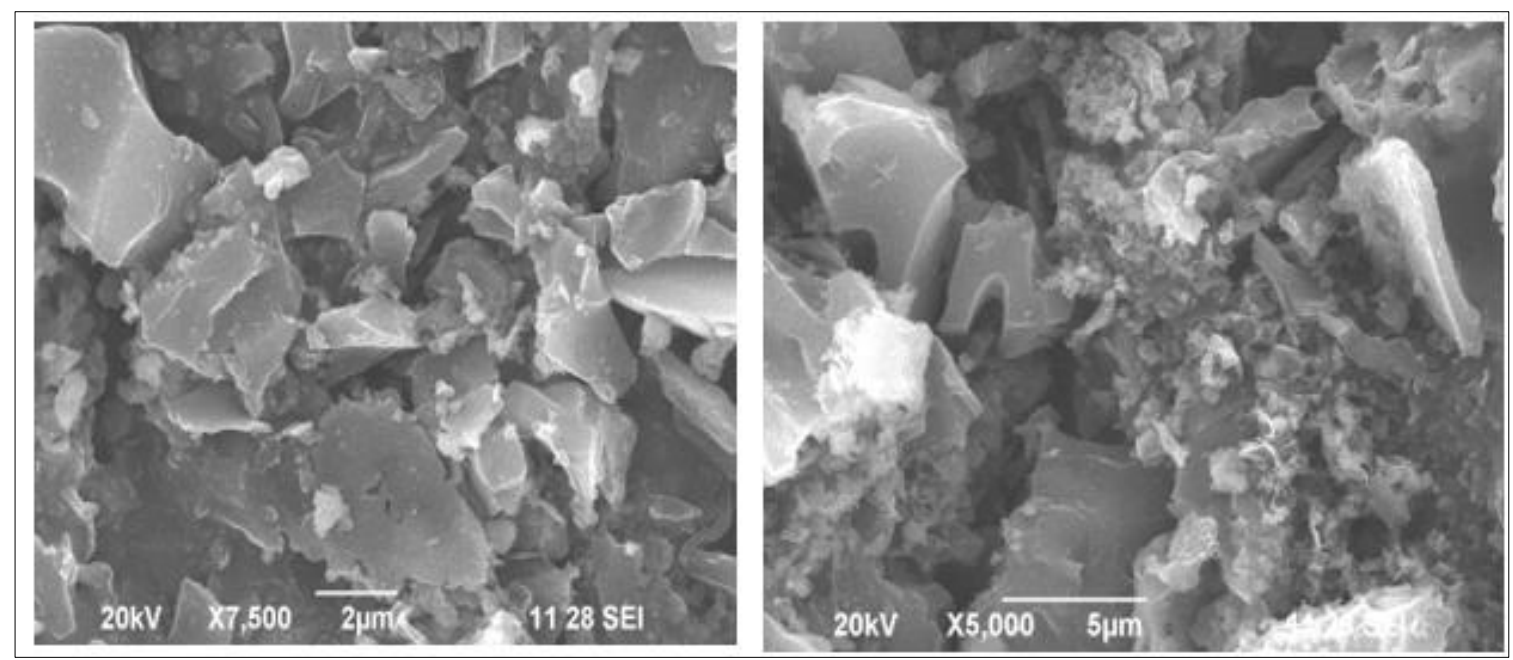

Figure 2. FESEM morphology of rice husk derived graphene

The XRD spectra are shown in Figure 3. At $26.3^{\circ}$, a strong diffraction peak emerged, corresponding to the breaking of amorphous carbon bonds and the development of graphene in the (002) plane. The absorbance spectra of suspended graphene particles are seen in Figure 4 . The $\pi$ - $\pi^{*}$ conjugation network is responsible for the absorbance peak at $265 \mathrm{~nm}$, indicating the formation of $\mathrm{sp}^{2}$ carbon atoms [24]. 


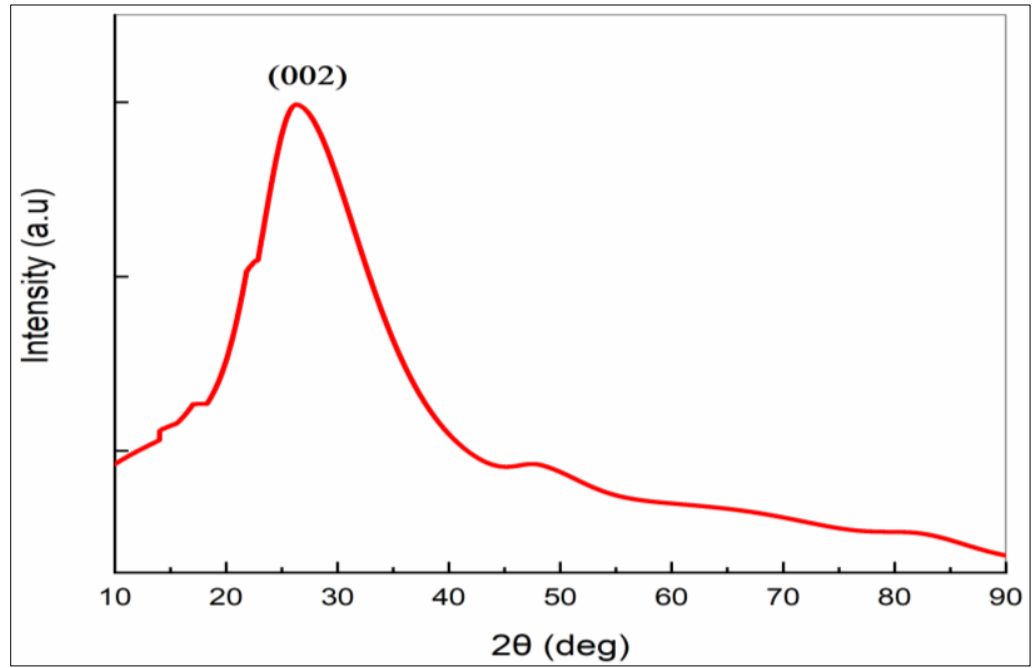

Figure 3. XRD spectra of the graphene at the (002) plane

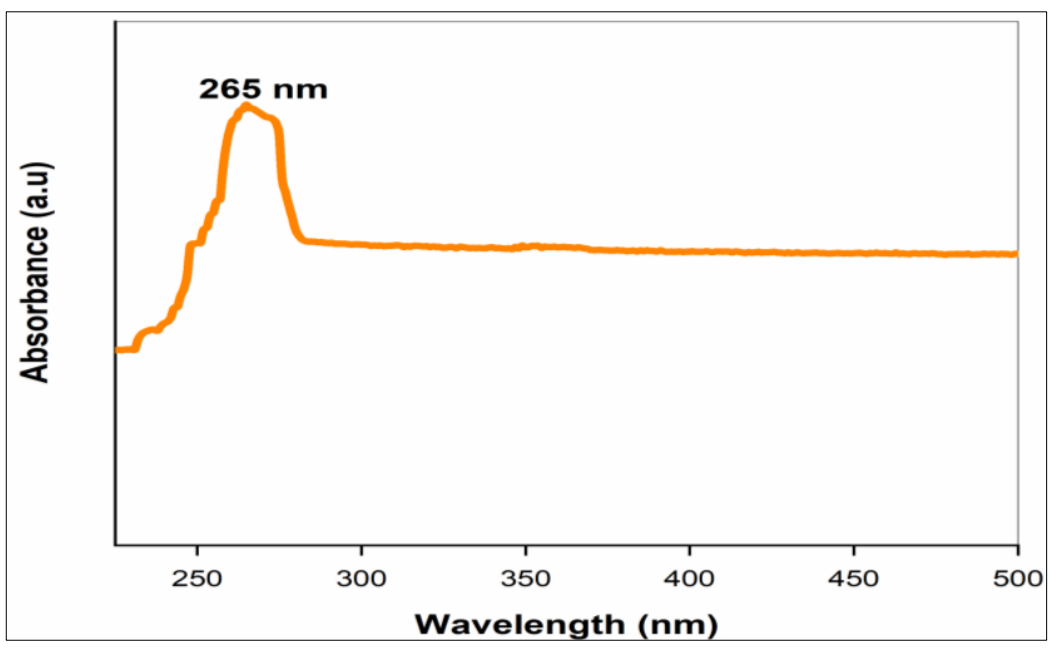

Figure 4. UV-Vis Spectra of graphene derived from rice husk

The distribution of particle sizes was calibrated using dynamic light scattering (DLS). The spatial amplitude of light scattered overtime is calculated using DLS. The average particle size distribution is about 60-70 nm, as seen in Figure 5. The role of functional groups in the prepared sample as determined by FTIR spectroscopy is seen in Figure 6 . The vibration stretches of symmetric $\mathrm{C}-\mathrm{H}$ bonds produce the peak at $2990 \mathrm{~cm}^{-1}$. The peak at wavelength $1612 \mathrm{~cm}^{-1}$ corresponds to aromatic $\mathrm{C}=\mathrm{C}$ stretching bonds, which are the skeleton of the graphinic structure and confirms the formation of graphene nanosheet [25].

The number of layers present is determined using Raman spectra, an essential method for the characterization of graphene. Three distinct peaks D band, G band, and the 2D band were observed at frequencies of 1354, 1588 and $2731 \mathrm{~cm}^{-1}$, respectively, as depicted in Figure 7. The 2D peak confirms the formation of $\mathrm{sp}^{2}$ hybridized carbon atoms (graphinic structure). The in-plane vibrations of C-C stretching are responsible for the $\mathrm{G}$ peak. The $\mathrm{D}$ peak in graphene corresponds to disordered structural and edge defects. Defectivity is shown by the ratio of the intensity of the D band ( $\left.\mathrm{I}_{\mathrm{D}}\right)$ to the intensity of the $\mathrm{G}$ band $\left(\mathrm{I}_{\mathrm{G}}\right)$. The $\mathrm{I}_{\mathrm{D}} / \mathrm{I}_{\mathrm{G}}$ ratio of 0.72 indicates that the hexagonal layer of carbon is disordered [26]. The ratio of peak $2 \mathrm{D}$ and $\mathrm{G}$ intensities $\left(\mathrm{I}_{2 \mathrm{D}} / \mathrm{I}_{\mathrm{G}}\right)$ is used to determine the number of graphene layers. The $\mathrm{I}_{2 \mathrm{D}} / \mathrm{I}_{\mathrm{G}}$ ratio of 0.84 indicates the formation of few-layer graphene nanosheets [27]. 


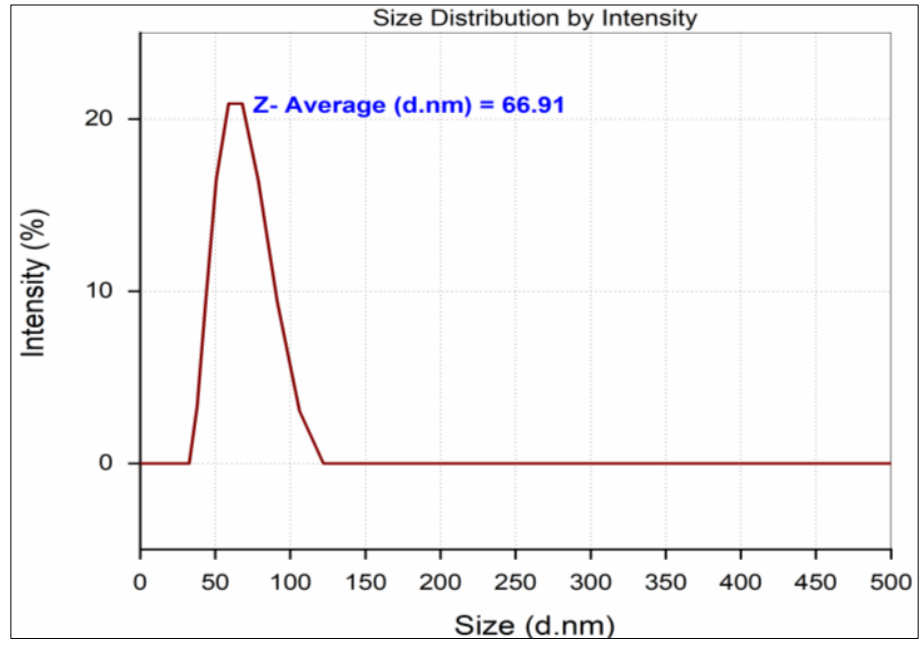

Figure 5. Particle size distribution of graphene

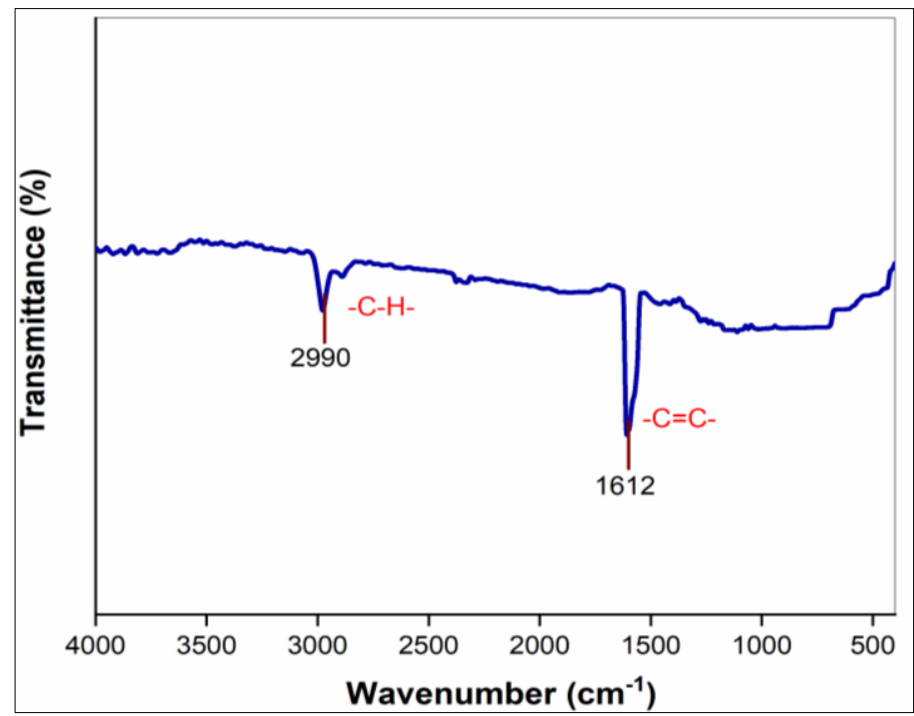

Figure 6. FTIR spectrum and the functional groups in the graphene

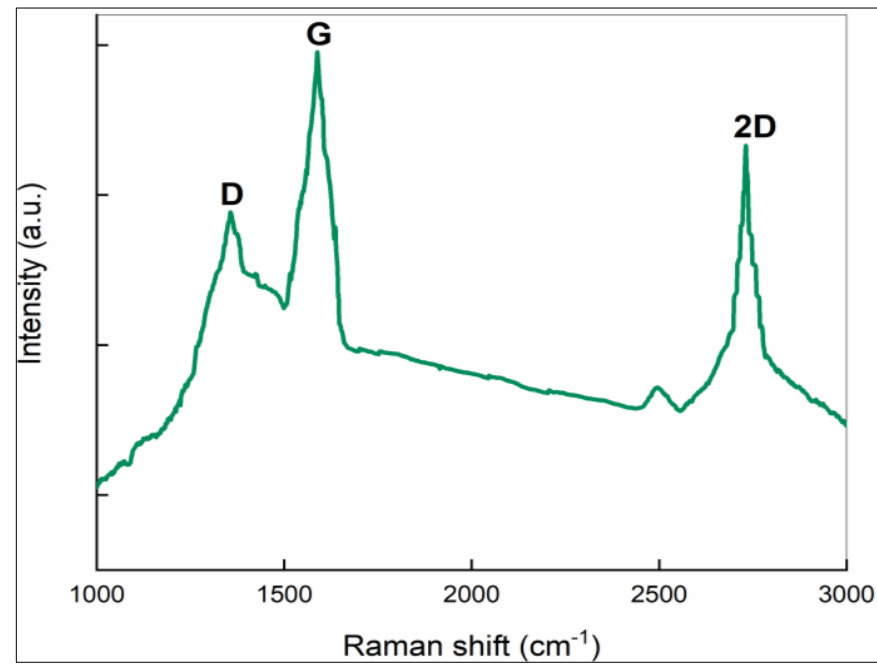

Figure 7. Raman spectra of the RHA derived graphene indicating the 2D, G and $\mathrm{D}$ bands 


\section{Conclusions}

Graphene nanosheets were successfully synthesized by eco-friendly method from agricultural waste (RHA) employing chemical activation using KOH. FESEM reveals that sharp edges graphene flakes were formed. X-ray diffraction peak at $26.3^{\circ}$ confirms the formation of graphinic structure. The presence of $\mathrm{sp}^{2}$ carbon atoms can be seen in the UV-Vis spectra. Graphene nanosheets ranged in size from 60 to 70 nanometers. The backbone of the graphene structure formed in the FTIR spectra indicates the formation of graphene. The intensity ratios and peaks of Raman spectra reveal the presence of layered graphene with fewer defects. Thus, the graphene synthesized from agricultural waste RHA is a costeffective method producing high-quality graphene finding applications in many fields.

Acknowledgements: Authors would like to acknowledge the Department of Nanoscience and Technology, Bharathiar University for extending their FESEM facility established under the DSTPURSE Programme, Department of Nanoscience and Technology, Tamilnadu Agricultural University for extending their TEM and Raman spectroscopy facilities, Bharat Ratna Prof.CNR RAO research centre, Avinashilingam Institute for Home Science and Higher Education for Women for extending their XRD and FTIR spectroscopy facilities.

\section{References}

1.FU, X., XU, L., LI, J., SUN, X., PENG, H., Flexible solar cells based on carbon nanomaterials, Carbon., 139, 2018, 1063-1073.

2.ZHANG, Y., JIAO, Y., LIAO, M., WANG, B., PENG, H., Carbon nanomaterials for flexible lithium ion batteries, Carbon., 124, 2017, 79-88.

3.KUILA, T., BOSE, S., MISHRA, A.K., KHANRA, P., KIM, N.H., LEE, J.H., Chemical functionalization of graphene and its applications, Prog. Mater Sci., 57, 2012, 1061-1105.

4.ZHONG, Y. L., TIAN, Z., SIMON, G. P., LI, D., Scalable production of graphene via wet chemistry: progress and challenges, Mater. Today., 18, 2015, 73-78.

5.GUO, Z., SONG, L., CHAI, G.B., LI, Z., LI, Y., WANG, Z., Multiscale finite element analyses on mechanical properties of graphene-reinforced composites, Mech. Adv. Mater. Struct., 26, 2019, 17351742.

6.CHEN, L., LI, J., CHEN, Z., GU, Z., YAN, L., ZHAO, F., ZHANG, A., Toxicological evaluation of graphene-family nanomaterials, J. Nanosci. Nanotechnol., 20(4), 2020, 1993-2006.

7.ZANDIATASHBAR, A., LEE, G.H., AN, S.J., LEE, S., MATHEW, N., TERRONES, M., HAYASHI, T., PICU, C.R., HONE, J. AND KORATKAR, N., Effect of defects on the intrinsic strength and stiffness of graphene, Nat. Commun., 5, 2014, 3186.

8.KONSTANTATOS, G., BADIOLI, M., GAUDREAU, L., OSMOND, J., BERNECHEA, M., DE ARQUER, F.P.G., GATTI, F., KOPPENS, F.H., Hybrid graphene-quantum dot phototransistors with ultrahigh gain, Nat. Nanotechnol., 7, 2012, 363-368.

9.MAO, S., PU, H., CHEN, J., Graphene oxide and its reduction: modeling and experimental progress, RSC Adv., 2, 2012, 2643-2662.

10.LEE, H., CHOI, T.K., LEE, Y.B., CHO, H.R., GHAFFARI, R., WANG, L., CHOI, H.J., CHUNG, T.D., LU, N., HYEON, T., CHOI, S.H., A graphene-based electrochemical device with thermoresponsive microneedles for diabetes monitoring and therapy, Nat. Nanotechnol. 11, 2016, 566-572.

11.PAPAGEORGIOU, D. G., KINLOCH, I. A., YOUNG, R. J., Mechanical properties of graphene and graphene-based nanocomposites, Prog. Mater Sci., 90, 2017, 75-127.

12.WU, Y. H., YU, T., SHEN, Z. X., Two-dimensional carbon nanostructures: Fundamental properties, synthesis, characterization, and potential applications, J. Appl. Phys., 108, 2010, 071301.

13.SU, C.Y., LU, A.Y., XU, Y., CHEN, F.R., KHLOBYSTOV, A.N., LI, L.J., High-quality thin graphene films from fast electrochemical exfoliation, ACS Nano, 5, 2011, 2332-2339.

14.LOTYA, M., KING, P. J., KHAN, U., DE, S., COLEMAN, J. N., High-concentration, surfactantstabilized graphene dispersions, ACS Nano, 4, 2010, 3155-3162. 
15.KARTICK, B., SRIVASTAVA, S. K. \& SRIVASTAVA, I., Green synthesis of graphene, J. Nanosci. Nanotechnol., 13, 2013, 4320-4324.

16.LEE, H.C., LIU, W.W., CHAI, S.P., MOHAMED, A.R., AZIZ, A., KHE, C.S., HIDAYAH, N.M., HASHIM, U., Review of the synthesis, transfer, characterization and growth mechanisms of single and multilayer graphene, $R S C A d v, 7,2017,15644-15693$.

17.HUSSAIN, S., IQBAL, M.W., PARK, J., AHMAD, M., SINGH, J., EOM, J., JUNG, J., Physical and electrical properties of graphene grown under different hydrogen flow in low pressure chemical vapor deposition, Nanoscale Res. Lett., 9, 2014, 546.

18.SAEED, M., ALSHAMMARI, Y., MAJEED, S. A., AL-NASRALLAH, E., Chemical Vapour Deposition of Graphene-Synthesis, Characterisation, and Applications: A Review, Molecules, 25, 2020, 3856.

19.EMTSEV, K.V., BOSTWICK, A., HORN, K., JOBST, J., KELLOGG, G.L., LEY, L., MCCHESNEY, J.L., OHTA, T., RESHANOV, S.A., RÖHRL, J., ROTENBERG, E., Towards wafersize graphene layers by atmospheric pressure graphitization of silicon carbide, Nat. Mater., 8, 2009, 203-207.

20.FERNANDES, I. J., CALHEIRO, D., KIELING, A.G., MORAES, C.A., ROCHA, T.L., BREHM, F.A., MODOLO, R.C., Characterization of rice husk ash produced using different biomass combustion techniques for energy, Fuel, 165, 2016, 351-359.

21.PODE, R., Potential applications of rice husk ash waste from rice husk biomass power plant, Renewable Sustainable Energy Rev, 53, 2016, 1468-1485.

22.SHEN, Y., Rice husk silica derived nanomaterials for sustainable applications, Renewable Sustainable Energy Rev, 80, 2017, 453-466.

23.MADDINEDI, S.B., MANDAL, B.K., VANKAYALA, R., KALLURU, P., PAMANJI, S.R., Bioinspired reduced graphene oxide nanosheets using Terminalia chebula seeds extract, Spectrochim. Acta A Mol. Biomol. Spectrosc., 145, 2015, 117-124.

24.JOHRA, F. T., LEE, J.W., JUNG, W.G., Facile and safe graphene preparation on solution based platform, J. Ind. Eng. Chem., 20, 2014, 2883-2887.

25.MEHMOOD, A., MUBARAK, N.M., KHALID, M., JAGADISH, P., WALVEKAR, R., ABDULLAH, E.C., Graphene/PVA buckypaper for strain sensing application, Sci. Rep., 10, 2020, 20106.

26.MURAMATSU, H., KIM, Y.A., YANG, K.S., CRUZ-SILVA, R., TODA, I., YAMADA, T., TERRONES, M., ENDO, M., HAYASHI, T., SAITOH, H., Rice husk-derived graphene with nanosized domains and clean edges, Small, 10, 2014, 2766-70.

27.SANKAR, S., LEE, H., JUNG, H., KIM, A., AHMED, A.T.A., INAMDAR, A.I., KIM, H., LEE, S., IM, H., KIM, D.Y., Ultrathin graphene nanosheets derived from rice husks for sustainable supercapacitor electrodes, New J. Chem., 41, 2017, 13792-13797.

Manuscript received: 7.06.2021 